\title{
From Documents to Data: Reinventing the HEC Montréal Library
}

\author{
BERNARD BIZIMANA \\ HEC Montréal Library, Montréal, Canada \\ bernard.bizimana@hec.ca
}

\begin{abstract}
The HEC Montréal Library found itself in the same difficult situation as many other business school libraries. The main challenge for the Library was to confirm its relevance by ensuring that it had a fundamental role to play in the School's learning and research community. It was in this context that the School's administrators asked for a complete revision of the Library's business model. They insisted that the Library make the changes necessary for it to meet the twenty-first century needs of professors, researchers, and students, particularly in the area of digital resources and services. Two years later, the Library has defined its new business model, one that is focused on providing research data and knowledge management services. This article describes the approaches that were used in this important restructuring project (change management, project management, value proposition design), the challenges that the Library has had to meet, the benefits for the HEC Montréal community as a whole, and the optimistic future that lies ahead for Library employees.
\end{abstract}

Keywords business library, new business model, data science, knowledge management

\section{Introduction}

The HEC Montréal Library finds itself in the same difficult situation as many other business school libraries. At a time of rapidly changing user needs and significant budget constraints, it is faced with complex challenges related to digital environments, and it has to confirm its relevance to the university community as a learning and research center. It is no surprise, therefore, that in the fall of 2016 the School's administrators called for a complete revision of the Library's business model. Eighteen months later, we are well on its way to a successful completion of this mandate with a new focus on providing research data and knowledge management services. This article describes the proactive approach that we have used to restructure the Library, the change management challenges that we have had to overcome, the benefits that this transformation has had for the Library and for the School community in general, and what we have planned for the future.

\section{General Context and the Mandate for Change}

HEC Montréal, a Canadian business school with AACSB, AMBA, and EFMD accreditation, is affiliated with the Université de Montréal. It offers a comprehensive set of study and training programs, including a BBA (with bilingual and trilingual streams), many MSc specializations, an MBA (in French and in English), an EMBA, an LLM, a PhD, and numerous executive education courses and seminars. With more than 9,000 full-time students, around 300 faculty and full-time lecturers, and over 600 administrative and support staff, the School is one of the largest business 
schools in the world. It has two existing campuses and a third one under construction in downtown Montréal.

When I became director of the HEC Montréal Library in 2016, the future of the Library was at stake. Our most important challenge was the disconnection from the research community. As one professor pointed out during a discussion about core services, the Library seemed out of touch with the twenty-first century world of scientific inquiry and was no longer "an adequate partner for researchers." Some professors, students, and School administrators were even questioning the necessity of having a university library at HEC Montréal in the first place. After all, a business school is not a humanities faculty. "We have less need of librarians than is probably the case for researchers in fields like history and literature," said the same professor. Twenty-five years before, the School community had been proud of the Library's impressive bilingual collection of business documents. Indeed, with approximately 320,000 documents, more than forty full-time employees (including four liaison librarians), and almost 54,000 square feet of naturally-lighted open-area floor space looking out onto beautiful parkland, we had been one of the largest and most successful business school libraries in Canada. However, after years of investing time and money into the Library, there was now a general consensus at HEC Montréal that the Library needed not only to update its overall service offerings, but also to ensure that professors, researchers, and students had improved access to digital resources and to the expertise necessary to exploit them to the fullest. In a word, the Library had to change its business model in order to become relevant in the contemporary data-centered world of university learning and research.

\section{Three Specific Challenges}

There were three specific challenges that had to be met in order for us to succeed in changing the Library's business model.

(1) Our first challenge was financial. During the last decade, there has been reduced government investment in education in Canada, and HEC Montréal has been seeking ways to reduce overall spending. It is also important to mention the $27 \%$ devaluation that the Canadian dollar has undergone since 2011, a devaluation that has had a drastic impact on the Library's capacity to acquire materials. It is in this context that HEC Montréal asked the Library to streamline its service offer and to ensure that the latter centered on helping the School's researchers maintain their competitive advantage. The Library had no choice but to undertake a major restructuring in order to succeed in significantly improving return on investment.

(2) Our second challenge was related to human resources training and development. The disconnect between the Library and the researcher community was such that we had to set about proving that librarians and other library personnel have an essential role to play at a major Canadian business school like HEC Montréal. This meant that we had to help our staff develop new competencies related to digital resources and expertise so that they were able to meet the data science and knowledge management needs of today's researchers.

(3) Our third challenge had to do with the problem of space management. HEC Montréal is currently searching for ways to optimize the use of space throughout the campus, and the 
Library's expansive study and book shelving areas are naturally seen as potential targets for new space management arrangements. To ensure that the Library was not physically dismantled, we had to develop a coherent space management strategy centered on the notion of an effective and at the same time diversified utilization of library space in line with the research and learning needs of professors, researchers, and students.

\section{The Approach to Change}

Discussing our service offerings with HEC Montréal faculty, researchers, and students, and with library staff was key to our approach to change. This conversation with stakeholders led to a consensus that change management and project management were critical to our success and that we had to build a team of managerial experts to succeed. Our project manager was a fulltime lecturer from the Department of Entrepreneurship and Innovation at HEC Montréal. He was accompanied by an MSc Student in Project Management and by the Director of Organizational Development at the Human Resources Office.

The team helped me identify the issues at stake in a project of this scope and made me aware of the importance of setting in place sound project management and change management practices. Together we clarified the mission and our global vision, and we discussed the best way to implement the project. Above all, we worked on mobilizing the team by setting out clearly defined objectives, ensuring that all staff members were aware of the fundamental importance of change, and showing everyone that restructuring our organization was not only a difficult challenge, but also an outstanding opportunity.

Naturally, many Library employees were worried that there might be a hidden agenda and that their jobs might be on the line. It is important to stress that during the preceding two years there had been a $25 \%$ reduction in Library staff, in large part through attrition with five employees retiring, and that the Library's disconnection from faculty members and researchers was perceived by some employees as a misunderstanding based on a lack of respect for their important contribution to academic scholarship. It was essential to assuage their fears and defuse any potential conflicts during this time of organizational transformation in order to turn resistance to change into enthusiastic support for this new opportunity to demonstrate the Library's relevance. This meant opening up lines of communication, providing forums for discussion, and ensuring that everyone had a clear understanding of the necessity of our mandate. Much of the dialogue took place in a series of formal and informal meetings, but employees were also encouraged to talk about the changes as often as possible among themselves. Some employees were immediately enthusiastic, others more anxious, but they pulled together with team spirit, in small groups and in larger meetings, to improve their understanding of the situation and to discuss their individual roles in the new Library mandate as well as the necessary reorientations and adjustments.

The project committee organized a kick-off meeting for all twenty-two Library staff members to help them understand the urgency of the situation, to explain to them the challenges faced by the Library, and to increase their awareness of the implications of the client-focused approach of our new service offerings. During the meeting, the project manager explained the two business model tools that had been chosen to reorient the Library's service offer: Business Model 
Generation (Osterwalder \& Pigneur, 2010) and Value Proposition Design (Osterwalder et al., 2014). The first is a practical visual tool that helps organizations determine the most appropriate business model for their clientele. It allows an organization to identify the elements (organizational resources, potential strategic partners, financing, etc.) that will allow it to generate viable value propositions. The second is a practical visual tool that helps organizations focus on client needs as the key factor in organizational success. The goal is to identify new products, services, activities, or behaviors that will be expected and valorized by clients.

It was at this point that the Director of the School, Michel Patry, invited me to present my new mandate to the Academic Council. Around the same time, I also had the opportunity to discuss it with key members of the Executive Committee. These meetings and discussions helped me to understand the full extent of the necessary changes that the Library had to make and of the challenging difficulties that it had to face. They also made it clear to me that the expectations of HEC Montréal amounted to an existential challenge. As we have already seen, the School was asking whether or not it actually needed to have a library. Although this message from upper management was unsettling, the meetings and discussions with these key deciders also allowed me to find very important allies of the Library in the HEC Montréal community. I realized that we were not alone and that the School was genuinely interested in having a library-one that had the capability to play a fundamental role in the highly competitive world of contemporary datacentered research.

In other words, I came to understand that transforming the HEC Montréal Library into a dynamic learning and research center would be a long and complex process that had to be accomplished in separate stages. Eventually, we divided the project into two main phases. The goal of the first phase, which we completed between December 2016 and April 2018, was to develop a detailed conception of client needs and to create the most effective business model for meeting these needs. The goal of the second phase, which began in May 2018 and which will be completed in April 2020, is to implement this new business model.

\section{Phase 1: Identifying Client Needs}

The key to success during phase 1 was identifying client segments and their specific needs. Here it is important to stress, once again, that the Library's new mandate gives priority to the research needs of our clientele. At the beginning of the identification process, it was obvious that the main client segments were professors and students (both in undergraduate and in graduate programs at the School). To develop a more thorough understanding of our client segments, I decided to meet with HEC Montréal faculty and PhD students individually. I also consulted with the various undergraduate and graduate student associations, and I asked an MSc student in marketing to do a survey for us to identify the learning and research needs of students. Altogether I had close to fifty individual meetings with professors, including all the department heads and academic program directors, as well as with PhD students. I had prolonged discussions with several of these persons, sometimes meeting them more than once to examine specific issues in greater detail. For example, I met with the head of the Department of Marketing several times to examine how to improve our ability to promote our service offerings more effectively. We also set up seven focus groups with undergraduate and graduate students completing degrees in various study programs. The focus group discussions revolved around 
issues like the service offerings for researchers, the accessibility and availability of digital content and digital expertise, and the use of physical and virtual spaces at the Library. After each focus group meeting, we had a brainstorming session that Library staff members attended in order to have the opportunity to listen to students explain their research and study needs. The central theme of these brainstorming sessions was defining the ideal library.

At the end of the discussions, consultations, and brainstorming sessions, the main client segments that stood out, in terms of the importance and the priority of their research needs, were the following: (1) professors as researchers; (2) professors as teachers; (3) PhD students; (4) MSc students; (5) undergraduate students; and (6) MBA students. It was clear that for each of these client segments data accessibility and mining capabilities and expertise had to become the core service offer. The Library had to reorient itself, not only in terms of providing research data services, but also in terms of overall knowledge management above and beyond data science technologies. It had to become a knowledge management center offering core data science services and expertise to the HEC Montréal learning and research community.

The second essential task that we had to undertake during Phase 1 was defining the most effective business model for transforming our service offerings and implementing the necessary structural changes at every level, including data science and knowledge management infrastructure and human resources training and development to ensure that our team was completely up to date in all areas of research science. It also meant that we had to improve our team by bringing in new players, including two data analysts with specialized training and experience in economic, financial, and management research in the business education sector. These two data analysts also brought us new expertise in information technology and statistics.

Inspired by the Dana Library at Rutgers University in Newark, New Jersey, the model that we decided on offers professors, researchers, and students a full range of data services (Wang, 2013). It is designed to meet their needs in data identification, acquisition, and management, and also to help reduce the amount of time that they devote to preparing data, a factor that gives it a great deal of added value. The key idea is to provide a one-stop service point that allows researchers to access data easily and to take full advantage of a wide array of interconnected data science and knowledge management support services. This model expands the information service offer of the traditional library considerably, both in terms of the number and the types of services provided and in terms of the overall coherence of the informationsharing structure. Eventually, it will integrate into this new Library structure already existing resources like HEC Montréal's Computer and Data Mining Laboratory.

Having identified the client segments and chosen the business model that would allow us to provide the service offer to meet their needs, it was time to set up individual meetings with key partners and stakeholders in the HEC Montréal community, in particular with executive administrators at the School, who had to be convinced of the validity of the proposed changes to the Library's main mission. With their support, it became possible to move forward with the implementation of these changes. 


\section{Phase 2: Implementing the New Business Model}

Phase 1 allowed us to identify our client segments and their specific needs, and to make a value proposition for each of these segments. As we have already seen, the new mandate is to transform the Library into a data science and knowledge management center, and the new business model involves going further than basic data management functions by offering professors, researchers, and students a one-stop service center that provides access to research data and to the related services, including data management. It will take us two years-from May 2018 until April 2020-to implement this new business model.

The main challenges for this implementation are in the areas of professional development and training, change management, and process management. Professional development and training is required to ensure that we have the organizational competencies necessary to make the new business model a reality. In collaboration with the Human Resources Office, one of our most important strategic partners, we are doing competency mapping to develop a coherent training program that will enable us to improve already existing competencies and to add new ones, particularly in the area of research data manipulation and analysis. Competency mapping is the process of clearly identifying the current skills and competencies of employees in order to determine strengths and weaknesses and ensure that an organization has the capacity to deliver the service offer defined by its business model. It usually involves asking the members of an organization to evaluate their competencies themselves using a systematic self-evaluation process that allows them to rate their own competency levels in different areas and then to set improvement goals.

At the beginning of Phase 2, we created an Excel sheet for competencies and each staff member was asked to auto-evaluate his or her current competency level in numerous areas on a scale of one to five. The Excel sheet was based in part on a list of core competencies for librarians created by the Canadian Association of Research Libraries (2010). Taking into consideration the data science focus of the new business model, I had to add several competencies, especially ones related to research data and knowledge management. All employees were asked to rate themselves with respect to a set of core competencies, and then for particular job positions, such as liaison librarian or library clerk, specific skills and competencies related to the main responsibilities of persons holding these positions were added both by the employees themselves and by their team leaders.

We are currently compiling and analyzing the data obtained from the competency mapping carried out by all twenty-two Library employees. The competency mapping analysis has already indicated that we need to create a new data analyst position, for which it has been necessary to hire a new employee. It has also led to the integration of the School's Computing and Data Mining Laboratory into the Library, so that we now have two full-time data analysts. These new additions to our staff represent a very positive event for the Library, which, as already mentioned, has undergone important human resources reductions during the last few years. The two new employees not only provide very significant new expertise in data science, which they can share with other employees, they also help to promote a spirit of optimism among team members, who now realize that the Library is moving forward with a coherent new mandate that offers interesting opportunities for career development. The next step will be to elaborate and 
validate an appropriate human resources training strategy that will enable us to meet future needs as determined by the new data science and knowledge management service structure at the core of our new business model.

This brings us to the second fundamental issue for Phase 2 of the implementation of the new business model: change management. The key concern here is ensuring that employees maintain a feeling of optimism and self-confidence. It is important to emphasize that the changes to the Library have been extremely challenging for all staff members. The more drastic changes are now in the past, so that it is not a question of relieving anxiety or combating resistance to change, but instead one of ensuring that Library employees continue to see the new mandate and business model as an excellent opportunity to increase their skill level and their competencies inside an updated modern library organization at the forefront of the contemporary world of data-centered research.

Change management also means proving our relevance to the HEC Montréal research community by demonstrating that the Library has a central role to play in enabling our professors, researchers, and students to perform at the highest levels in the extremely competitive world of contemporary academic research. This means that we have to develop a more precise definition of our data science and knowledge management service offerings and identify the best strategy for promoting this service offer in the School community. For example, in the near future our liaison librarians and our data analysts will be meeting to discuss ways to update and promote our research resource offerings for graduate students. Among other things, they will look at the possibility of offering new workshops on tools for statistical analysis, on using specialized databases like EIKON and SimplyAnalytics, and on the powerful new technologies available to researchers in the area of data visualization.

The third issue for the implementation of the new business model is process management. We have to update our processes in order to ensure that the new data science and knowledge management service offer is delivered coherently and that it is centered on client satisfaction. In a general context of long-term budget constraints, rapid technological change, and demanding service requests from its research clientele, the Library has to be prepared to optimize and to innovate as client needs develop and change. The new business model that we are implementing is clearly the right approach to change, but providing an efficient, cost-effective service offering must become a key concern for all Library employees in their day-to-day interactions with clients and with each other. During Phase 1, our focus groups and our survey on the learning and research needs of students revealed that we have to improve many aspects of our service delivery. We must overcome the silo mentality and work towards creating interconnected team work coherence and towards improving communications between our different teams. Library clients using our new data science and knowledge services must have a positive experience from beginning to end.

All twenty-two Library employees are currently doing intensive training in process management. The main objective of this training is to make them aware of the fundamental concepts of process management so that the Library can set in place organizational procedures that allow us to deliver our data science and knowledge management services in the most 
effective manner possible from a client satisfaction perspective. In particular, service offering sequences have to be become more fluid, which sometimes means eliminating unnecessary steps and procedures. It is not only the quality of services that matters, but also the time frame in which they can be delivered and the cost of providing them, both for the user and for the Library. From now on, process management will be an integral part of operations management at the Library.

It is also important to mention that we are reinventing the Library from a space management perspective. Storing documents and providing study areas is not a sufficient space utilization strategy for a twenty-first century library. Over the course of the next academic year, a study will be conducted on introducing new space management paradigms that are more in line with the current teaching and research mission of HEC Montréal. As previously mentioned, one important space management change that has already been confirmed is the integration of the Computing and Data Mining Laboratory into the Library space. The Mathematics and Statistics Help Center will also be coming to the Library. This is not merely a physical change to Library space use, it is also a fundamental aspect of the new mandate to transform the Library into a data science and knowledge management hub where professors, researchers, and students can meet together and pursue their scientific goals.

We are still at the beginning of the implementation process, and many challenges lie ahead, but the new business model that places data science and knowledge management at the heart of our mandate is now a reality, not only for Library employees who are engaged in updating their skills and competencies in order to ensure the success of our new service offer, but also for the HEC Montréal learning and research community as whole. Professors, researchers, students, and upper management are showing renewed interest in the Library's fundamental contribution to learning and research. They understand why the School needs a library.

\section{Conclusion}

For the last two years, the HEC Montréal Library has been engaged in a process of profound transformation. Before we began, the disconnection between our service offer and the needs of our clientele, the School's learning and research community, threatened to deprive the Library of the scientific relevance that any functioning library needs in order to thrive in a business school today. It was essential to act quickly and decisively, for if we wanted to survive this existential crisis, we had no choice but to define a new business model for the Library in order to ensure that its service offer was completely in line with the twenty-first century needs of the learning and research community at HEC Montréal. This transformation has come with many challenges, but it represents a wonderful occasion to re-establish a positive working relationship with faculty, to prove that the Library and its staff have a fundamental role to play in the HEC Montreal community as a whole, and to reinvent other important dimensions of our service offerings through initiatives like creating alternative space management strategies and introducing new training programs to help students improve their data science research skills. To a large extent, we have had to break new ground. Switching from a document-centered model to a research data and knowledge management model is a multifaceted long-term project that involves complex professional development and change management issues. No two business school libraries will make this modernizing transition in exactly the same way, but the numerous positive 
Ticker: The Academic Business Librarianship Review, 3:2 (2019)

http://dx.doi.org/10.3998/ticker.16481003.0003.206

(c) 2019 Bernard Bizimana

changes that are currently taking place at the HEC Montréal Library make one thing clear: those that adopt a proactive approach to these daunting challenges have a very bright future in the contemporary world of academic learning and research.

\section{References}

Canadian Association of Research Libraries. (2010). Core competencies for 21st century CARL librarians. http://www.carl-abrc.ca/doc/core comp profile-e.pdf.

Osterwalder, A. \& Pigneur, Y. (2010). Business model generation: A handbook for visionaries, game changers, and challengers. Hoboken, NJ: Wiley.

Osterwalder, A., Pigneur, Y., Bernarda, G., Smith, A., \& Papadakos, T. (2014). Value proposition design: How to create products and services customers want. Hoboken, NJ: Wiley.

Wang, M. (2013). Supporting the research process through expanded library data services. Program, 47(3), 282-303. 